\title{
Evaluation of the Serum Levels of IL-1 in Type 2 Diabetic Patients with and without Diabetic Nephropathy
}

\author{
Nahid Niknami ${ }^{1}$, Melody Omraninava ${ }^{2 *}$, Nazanin Mirzaei $^{3}$ \\ ${ }^{1}$ Internal Medicine, Tonekabon Branch, Islamic Azad University, Tonekabon, Iran \\ ${ }^{2}$ Infectious Disease, Sari Branch, Islamic Azad University, Sari, Iran \\ ${ }^{3}$ Pathology, Tonekabon Branch, Islamic Azad University, Tonekabon, Iran \\ Email: *melodyomraninava@yahoo.com
}

How to cite this paper: Niknami, N., Omraninava, M. and Mirzaei, N. (2018) Evaluation of the Serum Levels of IL-1 in Type 2 Diabetic Patients with and without Diabetic Nephropathy. Journal of Diabetes Mellitus, 8, 54-60.

https://doi.org/10.4236/jdm.2018.82006

Received: November 15, 2017

Accepted: May 21, 2018

Published: May 24, 2018

Copyright $\odot 2018$ by authors and Scientific Research Publishing Inc. This work is licensed under the Creative Commons Attribution International License (CC BY 4.0).

http://creativecommons.org/licenses/by/4.0/

\begin{abstract}
Background: Diabetic nephropathy (DN) has been regarded as an important cause of morbidity in patients with type 2 diabetes (T2D). Immune system components are modulated during T2D, with the most apparent modifications in adipose tissue, pancreatic islets, liver, and circulating leukocytes. The aim of this survey was to evaluate the role of IL-1 in the etiopathogenesis of nephropathic T2D. Methods: In this case-control investigation, the study population consisted of $58 \mathrm{~T} 2 \mathrm{D}$ patients with proteinuria (nephropathy T2D cases) as the case group and 76 T2D cases without proteinuria (non-nephropathy T2D cases) as the control group. Blood samples were obtained from all individuals and ELISA approach was carried out to measure IL-1 levels in samples. Results: Our experiments demonstrated that T2D patients with nephropathy had significantly increased levels of IL-1 in their blood in comparison to T2D patients without nephropathy. Conclusions: It seems that IL-1 plays a role in the etiopathogenesis of nephropathy in T2D patients, requiring further implementation to vivid disclose of the inflammation in this context.
\end{abstract}

\section{Keywords}

Inflammation, Interleukin 1, Nephropathy, Type 2 Diabetes

\section{Introduction}

Kidney failure due to diabetes is the most important cause of failure throughout the world and is the most important cause of premature death in diabetic patients [1]. In approximately $40 \%$ of cases, the cause of the end stage renal disease 
(ESRD) is diabetes, which results in a cost more than 4 billion dollars a year in the United States [2]. Additionally, about 30\% of people with type 1 diabetes (T1D) and a lower percentage of people with type 2 diabetes (T2D) are ultimately diagnosed with ESRD. However, due to the higher prevalence of T2D than T1D, the overall number of cases with ESRD is greater in T2D. The primary evidence of nephropathy indicates the presence of very low levels of albumin in the urine $(20 \mu \mathrm{g} / \mathrm{min}$ or $>30 \mathrm{mg} /$ day $)$, which is called microalbuminuria, and the patient with microalbuminuria is considered as the primary nephropathy [3]. The relative risk of permanent microalbuminuria occurrence in T1D and T2D has been reported to be 3 and 2.78, respectively [4] [5].

Microalbuminuria trend in T1D shows a progressive increase in urine protein to severe proteinuria (more than $300 \mathrm{mg} / \mathrm{d}$ ) or severe nephropathy. When severe proteinuria is seen, there is a steady decrease in glomerular filtration rate (GFR). Nephropathy caused by T2D is different from T1D. Microalbuminuria or severe nephropathy may be present during the diagnosis of T2D [6]. Hypertension is more commonly associated with microalbuminuria or severe nephropathy, and microalbuminuria in T2D is less prognostic of diabetic nephropathy and progression to severe nephropathy. It should be noted that albuminuria in T2D may be secondary to non-diabetes related factors, such as hypertension, congestive heart failure, and diseases or infections of prostate. Suitable control of blood glucose reduces the rate of progression of microalbuminuria in both T1D and T2D [7].

T2D is typically associated with inflammatory mediator's overproduction, and a high level of inflammatory process occurs during T2D [8]. Inflammatory mediators are proteins that display altered production during response to inflammatory processes or stresses such as infection, surgical injuries, trauma or tissue necrosis. Increased plasma levels of complement components lead to local accumulation of neutrophils, macrophages, and plasma proteins, which play roles to eliminate infectious agents, remove cell residues or foreign agents, and repair damage [9]. Overall, these reactions cause fever, leukocyte accumulation in the inflammatory position, muscle catabolism, and a change in the production of certain proteins by reducing albumin. As a result, responding to tissue inflammation culminates in recruitment and local accumulation of inflammatory cells like neutrophils and macrophages. At the same time, the production of a number of proteins is reduced (negative reactors). Among the negative markers can enumerate transferrin and transthyretin, in addition to albumin. Negative reactants of the acute phase are less synthesized because of the increased ability of the liver to produce positive reactants of acute phase [10].

Interleukin (IL)-1 is an inflammatory cytokine produced by active macrophages and affects the expression of IL-2 receptors. IL-2 levels increase simultaneously with tumor necrosis factor (TNF)- $\alpha$ in septic shock or in cerebrospinal fluid in patients with multiple meningitis or multiple sclerosis [11].

Since nephropathy is a cause for great concern in people with diabetes, several studies have been conducted on the relationship between inflammation and 
nephropathic reactions that have led to controversial results. In sum, most studies have shown that acute phase markers increase in patients with nephropathy and microalbuminuria [12]. Regarding the fact that T2D is a public health problem worldwide and other organ's complications upon T2D are one of the medical challenges of recent decades, and since the role of inflammatory factors in progressing towards diabetic nephropathy has not been studied in Iran, we aimed to investigate these factors.

\section{Study Subjects and Methods}

This is an analytical and case-control study and since interventional factors can be effective in the final results, this approach is beneficial by matching and to answer the question about the etiology of nephropathy in T2D patients. The study population consisted of58 T2D patients with proteinuria (nephropathy $\mathrm{T} 2 \mathrm{D}$ cases) as the case group and $76 \mathrm{~T} 2 \mathrm{D}$ cases without proteinuria (non-nephropathy T2D cases) as the control group. T2D diagnosis was carried out based on the American Diabetes Association (ADA) criteria [13]. Patients and controls were selected among the individuals referred to Ramsar Imam Sajad hospital. The protocol of the study was ethically approved by the Ethical Committee and written informed consent forms was obtained from all the participants.

The conditions for the exclusion of patients from the study include patients with uncontrolled hypertension, hyperlipidemia, urinary tract infections, and heart failure, as well as patients with inflammatory diseases.

The clinical characteristics of all study subjects are shown in Table 1. Proteinuria was characterized based on 24-hour urine containing more than 150 $\mathrm{mg} / \mathrm{dl}$ urine protein. Patients were referred to the specialized diabetes clinic to control diabetes. From these two groups, a fasting blood samples were obtained after an overnight fast. After blood sampling, serums were immediately separated and stored at $-80^{\circ}$ until the assays were performed. Serums were used to measure IL-1 concentration using ELISA method (Enzyme-linked Immunosorbent Assay) by Biovendor Laboratorial kit made by Biovendor Company, Czech.

\section{Statistical Analysis}

The statistical analysis was performed using the SPSS v.22. The data were expressed as mean \pm standard error of the mean (SEM) and median for scale and nominal data, respectively. For evaluation of the scale data for normality, the Kolmogorov-Smirnov test was performed. Comparisons of the groups were examined by independent sample $t$-test. Fisher's exact test was carried out to perform cross-tab analysis of nominal variables. $\mathrm{p}$ values below 0.05 were considered to be statistically significant.

\section{Results}

In this study, 58 and 76 cases of T2D patients with and without nephropathy, 
Table 1. Characteristics of the studied population and their comparisons between the groups.

\begin{tabular}{cccc}
\hline Characteristics & $\begin{array}{c}\text { T2D cases with } \\
\text { Nephropathy }(\mathbf{n}=\mathbf{5 8})\end{array}$ & $\begin{array}{c}\text { T2D cases without } \\
\text { Nephropathy (n= 76) }\end{array}$ & P value \\
\hline Male N (\%) & $32(55 \%)$ & $19(25 \%)$ & 0.00032 \\
Female N (\%) & $26(45 \%)$ & $57(75 \%)$ & \\
Age (year) & $15(26 \%)$ & $23(30.5 \%)$ & 0.769 \\
$40-50$ & $26(45 \%)$ & $36(48 \%)$ & \\
$51-60$ & $10(17 \%)$ & $11(14.5 \%)$ & \\
$61-70$ & $7(12 \%)$ & $6(7 \%)$ & 0.021 \\
$71-80$ & $15.95 \pm 3.04$ & $9.38 \pm 0.74$ & \\
\hline
\end{tabular}

${ }^{\star}$ Data was shown as Mean \pm SEM.

Table 2. IL-1 level between different categories of T2D patients.

\begin{tabular}{ccc}
\hline Category & IL-1 levels $(\mathrm{pg} / \mathrm{ml})^{*}$ & P value \\
\hline & Nephropathy & \\
T2D cases with Nephropathy & $15.95 \pm 3.04$ & 0.021 \\
T2D cases without Nephropathy & $9.38 \pm 0.74$ & \\
& Gender & 0.019 \\
Male & $16.41 \pm 3.42$ & \\
Female & $9.65 \pm 0.75$ & \\
& Age (year) & \\
$40-50$ & $13.54 \pm 4.17$ & \\
$51-60$ & $11.11 \pm 1.03$ & \\
$61-70$ & $11.87 \pm 2.70$ & \\
$71-80$ & $14.28 \pm 4.69$ &
\end{tabular}

${ }^{*}$ Data was shown as Mean \pm SEM.

respectively, were selected for evaluations. In T2D patients with and without nephropathy, there were 32 (55\%) and 19 (25\%) males, respectively. Moreover, $26(45 \%)$ and 57 (75\%) female patients were detected in T2D groups with and without nephropathy, respectively. Our data demonstrated that there was a significant difference $(P=0.00032)$ in being male of female and having nephropathy in T2D patients (Table 1).

Study subjects were categorized into 4 groups based on their age. It was observed that T2D cases with nephropathy were $15(26 \%)$ cases in 40 - 50 years, 26 $(45 \%)$ in $51-60,10(17 \%)$ in $61-70$, and $7(12 \%)$ in $71-80$ years old. On the other hand, T2D cases without nephropathy were identified to be $23(30.5 \%)$ cases in 40 - 50 years old, $36(48 \%)$ cases in $51-60,11(14.5 \%)$ in $61-70$, and 6 (7\%) cases in $71-80$ years old category. However, there was no significant dif- 
ference in age between cases and controls (Table 1).

T2D cases with nephropathy had $15.95 \pm 3.04 \mathrm{pg} / \mathrm{ml}$ of IL-1 in their serum samples which was significantly higher than $9.38 \pm 0.74 \mathrm{pg} / \mathrm{ml}$ in T2D cases without nephropathy $(P=0.021)$. Moreover, male T2D cases indicated significantly increased IL-1 level compared with female T2D cases $(16.41 \pm 3.42$ vs. $9.65 \pm 0.75 ; P=0.019)$. Nonetheless, no significant difference was observed in IL-1 levels of T2D patients with different age categories (Table 2).

\section{Discussion}

Over the last decades, diabetes mellitus, particularly T2D, has been considered as major public health issue, which has gained epidemic proportions because of fast growing rates of this disease all over the world. There are a number of post-T2D organ complications will be of great importance for medical and health community in decades coming ahead. Among these complications, is diabetic nephropathy, which stands as the single most prevalent cause of ESRD [14].

Still, the precise mechanisms underlying chronic inflammation stimulation of T2D have not been elucidated. Nonetheless, it has been documented that adipose tissue can produce and release the important inflammatory cytokines, such as TNF- $\alpha$, IL-1, and IL- 6 . Moreover, the inflammatory presentations have been associated with body fat mass in various cases. Studies have shown that acute phase reactants and inflammatory cytokines are involved in several metabolic pathways underlying insulin resistance, such as reactive oxygen species (ROS), lipoprotein lipase function, and adipocyte action [15]. As a consequence, activated innate immunity as well as inflammation have been regarded as pertinent factors in the diabetes etiopathogenesis, with satisfactory evidence that T2D may be underpinned through inflammatory responses [15] [16].

IL-1 is a proinflammatory cytokine, which has been demonstrated to be an effector component of pancreatic beta-cell destruction during inflammation resulting in T1D [17]. In addition, IL-1 interacts with the function of pancreatic beta-cells and triggers the apoptosis of these cells [18]. Pancreatic cells obtained from patients with T2D have demonstrated production of IL-1 from beta cells [19]. In vitro experiments have indicated that high glucose levels cause stimulation of IL-1 synthesize and release from pancreatic beta cells, which is subsequent by functional impairment and apoptosis of these cells [19] [20] [21]. These observations simply show that production of inflammatory mediators from beta cells may play a role in T2D pathogenesis; hence, IL-1 can be considered as a potential therapeutic target for inhibiting beta cell function in these patients, as IL-1 antagonist has been promising in treatment of T2D patients [22].

Our major finding was in accord with the evidence published previously with regard to the role of IL- 1 in the pathogenesis of T2D diseases with nephropathy [8]. We identified that serum level of IL-1 was increases in T2D patients with nephropathy in comparison to the T2D patients without nephropathy. This implies to the role of IL-1 in the pathogenesis of nephropathy in T2D patients irre- 
levant to the differences in population type and shed further light on the role of this cytokine in pathogenesis and complications of nephropathy in patients with T2D.

There are some limitations and caveats in this study that need to be addressed. Firstly, the sample size was low. Moreover, we could not evaluate more clinical characteristics of the patients like creatinine levels, body mass index, and other inflammatory cytokines. Evaluating these factors could have escalated the power of this investigation.

Considering all the facts, we intended to evaluate the serum levels of IL-1 in T2D patients with and without nephropathy to search for the role of this inflammatory cytokine in the complications of T2D and its relationship with nephropathy. We noticed that serum level of IL-1 was increased significantly in T2D patients with nephropathy compared with T2D cases without nephropathy. It seems that IL-1 is involved in the pathogenesis of nephropathy in T2D patients. However, evaluation of other inflammatory mediators will be worthwhile in future studies to disclose exact role of these agents in arising nephropathy in Iranian $\mathrm{T} 2 \mathrm{D}$ patients.

\section{References}

[1] Levey, A.S., Coresh, J., Balk, E., Kausz, A.T., Levin, A., Steffes, M.W., et al. (2003) National Kidney Foundation Practice Guidelines for Chronic Kidney Disease: Evaluation, Classification, and Stratification. Annals of Internal Medicine, 139, 137-147. https://doi.org/10.7326/0003-4819-139-2-200307150-00013

[2] Foley, R.N. and Collins, A.J. (2007) End-Stage Renal Disease in the United States: An Update from the United States Renal Data System. Journal of the American Society of Nephrology, 18, 2644-2648. https://doi.org/10.1681/ASN.2007020220

[3] Rosario, R.F. and Wesson, D.E. (2006) Primary Hypertension and Nephropathy. Current Opinion in Nephrology and Hypertension, 15, 130-134.

https://doi.org/10.1097/01.mnh.0000214771.88737.ee

[4] Verma, M.K., Kumar, P., Sharma, P., Singh, V. and Singh, S.P. (2017) Study of Microalbuminuria as Early Risk Marker of Nephropathy in Type 2 Diabetic Subjects. International Journal of Research in Medical Sciences, 5, 3161-3166. https://doi.org/10.18203/2320-6012.ijrms20173006

[5] Hovind, P., Tarnow, L., Rossing, P., Graae, M., Torp, I., Binder, C., et al. (2004) Predictors for the Development of Microalbuminuria and Macroalbuminuria in $\mathrm{Pa}$ tients with Type 1 Diabetes: Inception Cohort Study. BMJ, 328, 1105. https://doi.org/10.1136/bmj.38070.450891.FE

[6] Adler, A.I., Stevens, R.J., Manley, S.E., Bilous, R.W., Cull, C.A., Holman, R.R., et al. (2003) Development and Progression of Nephropathy in Type 2 Diabetes: the United Kingdom Prospective Diabetes Study (UKPDS 64). Kidney International, 63, 225-232. https://doi.org/10.1046/j.1523-1755.2003.00712.x

[7] Bate, K.L. and Jerums, G. (2003) 3: Preventing Complications of Diabetes. Medical Journal of Australia, 179, 498-505.

[8] Donath, M.Y. and Shoelson, S.E. (2011) Type 2 Diabetes as an Inflammatory Disease. Nature Reviews Immunology, 11, 98-107. https://doi.org/10.1038/nri2925

[9] Hotamisligil, G.S. (2006) Inflammation and Metabolic Disorders. Nature, 444, 
860-867. https://doi.org/10.1038/nature05485

[10] Steel, D.M. and Whitehead, A.S. (1994) The Major Acute Phase Reactants: C-Reactive Protein, Serum Amyloid P Component and Serum Amyloid A Protein. Immunology today, 15, 81-88. https://doi.org/10.1016/0167-5699(94)90138-4

[11] Strowig, T., Henao-Mejia, J., Elinav, E. and Flavell, R. (2012) Inflammasomes in Health and Disease. Nature, 481, 278-286. https://doi.org/10.1038/nature10759

[12] Navarro-González, J.F. and Mora-Fernández, C. (2008) The Role of Inflammatory Cytokines in Diabetic Nephropathy. Journal of the American Society of Nephrology, 19, 433-442. https://doi.org/10.1681/ASN.2007091048

[13] Association, A.D. (2014) Diagnosis and Classification of Diabetes Mellitus. Diabetes Care, 37, S81-S90. https://doi.org/10.2337/dc14-S081

[14] Ritz, E., Rychlík, I., Locatelli, F. and Halimi, S. (1999) End-Stage Renal Failure in Type 2 Diabetes: A Medical Catastrophe of Worldwide Dimensions. American Journal of Kidney Diseases, 34, 795-808. https://doi.org/10.1016/S0272-6386(99)70035-1

[15] Crook, M. (2004) Type 2 Diabetes Mellitus: A Disease of the Innate Immune System? An Update. Diabetic Medicine, 21, 203-207. https://doi.org/10.1046/j.1464-5491.2003.01030.x

[16] Pickup, J.C. (2004) Inflammation and Activated Innate Immunity in the Pathogenesis of Type 2 Diabetes. Diabetes Care, 27, 813-823. https://doi.org/10.2337/diacare.27.3.813

[17] Mandrup-Poulsen, T. (1996) The Role of Interleukin-1 in the Pathogenesis of IDDM. Diabetologia, 39, 1005-1029. https://doi.org/10.1007/BF00400649

[18] Bendtzen, K., Mandrup-Poulsen, T., Nerup, J., Nielsen, J.H., Dinarello, C.A. and Svenson, M. (1986) Cytotoxicity of Human pI 7 Interleukin-1 for Pancreatic Islets of Langerhans. Science, 232, 1545-1547. https://doi.org/10.1126/science.3086977

[19] Maedler, K., Sergeev, P., Ris, F., Oberholzer, J., Joller-Jemelka, H.I., Spinas, G.A., et al. (2002) Glucose-Induced $\beta$ Cell Production of IL-1 $\beta$ Contributes to Glucotoxicity in Human Pancreatic Islets. The Journal of Clinical Investigation, 110, 851. https://doi.org/10.1172/JCI200215318

[20] Maedler, K., Spinas, G.A., Lehmann, R., Sergeev, P., Weber, M., Fontana, A., et al. (2001) Glucose Induces $\beta$-Cell Apoptosis via Upregulation of the Fas Receptor in Human Islets. Diabetes, 50, 1683-1690. https://doi.org/10.2337/diabetes.50.8.1683

[21] Maedler, K., Størling, J., Sturis, J., Zuellig, R.A., Spinas, G.A., Arkhammar, P.O., et al. (2004) Glucose-and Interleukin- $\beta$-Induced $\beta$-Cell Apoptosis Requires $\mathrm{Ca}^{2+}$ Influx and Extracellular Signal-Regulated Kinase (ERK) 1/2 Activation and Is Prevented by a Sulfonylurea Receptor 1/Inwardly Rectifying K+ Channel 6.2 (SUR/Kir6.2) Selective Potassium Channel Opener in Human Islets. Diabetes, 53, 1706-1713. https://doi.org/10.2337/diabetes.53.7.1706

[22] Larsen, C.M., Faulenbach, M., Vaag, A., Vølund, A., Ehses, J.A., Seifert, B., et al. (2007) Interleukin-1-Receptor Antagonist in Type 2 Diabetes Mellitus. New England Journal of Medicine, 356, 1517-1526. https://doi.org/10.1056/NEJMoa065213 